\title{
GESTÃO DO RELACIONAMENTO COM O CLIENTE EM MERCADOS BUSINESS-TO-BUSINESS
}

\section{CUSTOMER RELATIONSHIP MANAGEMENT APPLIED TO BUSINESS-TO-BUSINESS}

\author{
Vanderli Correia Prieto \\ Mestranda do Depto. de Eng. de Produção - Escola Politécnica da USP \\ Av. Prof. Almeida Prado, 128 Tr. 2 Biênio $2^{\circ}$ andar - 05508-900 São Paulo,SP Brasil \\ Tel(011) 30915363 Fax 30915399 e-mail: vanderli@prietoassociados.com.br

\section{Marly Monteiro de Carvalho} \\ Prof $^{a}$. Dra ${ }^{a}$ do Depto. de Eng. Produção - Escola Politécnica da USP \\ Av. Prof. Almeida Prado, 128 Tr. 2 Biênio $2^{\circ}$ andar - 05508-900 São Paulo,SP Brasil \\ Tel (011) 30915363 R. 303 Fax 30915399 e-mail: marlymc@usp.br
}

\begin{abstract}
RESUMO
Este artigo trata da aplicação do conceito de Gestão do Relacionamento com o Cliente (CRM) no segmento business-to-business. $\mathrm{O}$ conceito representa o desafio de enxergar cada cliente como se fosse o seu próprio mercado. No segmento business-to-business a transação de valor econômico é alta e a perda de um único cliente pode resultar em impacto significativamente negativo para as receitas. Isto demanda um investimento ainda maior em construir e manter um relacionamento com os clientes. O objetivo deste artigo é indicar aspectos críticos na implementação do CRM relacionados à estratégia da empresa e à estrutura de CRM. O artigo descreve uma experiência com a automação da força de vendas (SFA), que é uma das dimensões tecnológicas do CRM. A metodologia de pesquisa adotada foi o estudo de caso em uma empresa global de engenharia eletroeletrônica. Neste artigo primeiramente são introduzidos os conceitos de CRM e SFA e então são discutidos aspectos da implementação do CRM no segmento business-to-business. As conclusões nos permitem perceber que a estrutura de CRM provê maior produtividade à área de Vendas e transfere o controle da gestão do relacionamento com o cliente do vendedor para a empresa e que tais resultados são apoiados em ações estratégicas sistematicamente conduzidas.
\end{abstract}

Palavras-chave: gestão do relacionamento com o cliente, business-to-business. 


\begin{abstract}
This article discusses the application of the Customer Relationship Management (CRM) concept in business-to-business. The concept represents a challenge to face every customer as its own market. In business-to-business the transactions economic value is high and the loss of a single customer can result in a very negative impact in the company billing. This means that business should invest far more in building and supporting a relationship with the customers. The aim of this paper is to indicate the main critical issues of implementation of the CRM related to the company strategy and the specific CRM structure. It describes an experience with Sales Force Automation (SFA), which is one of the technological dimensions of CRM. The adopted methodological approach was a case study in a global electro electronic industry. In this article firstly are introduced the concepts of CRM and SFA and then are discussed CRM implementation aspects in business-to-business. The conclusions allow realizing that the implemented CRM structure gives more productivity to the Sales area and transfer the customer relationship management control of the salesman to company, and that such results have the endorsement of strategical actions that systematically are carried through.
\end{abstract}

Key-words: customer relationship management, business-to-business.

\title{
1. INTRODUÇÃO
}

A gestão do relacionamento com o cliente ou CRM - Customer Relationship Management - é uma abordagem com a intenção de implementar mudanças que venham a melhorar e prolongar, por que não dizer, perpetuar o relacionamento com o cliente. A prática de desenvolver ações para aumentar o conhecimento sobre os hábitos de consumo do cliente, entregar o produto ou serviço certo e, com isto reter os clientes não é necessariamente nova. Para exemplificar, podemos citar o caso dos fenícios, hábeis comerciantes que não por acaso sabiam que os egípcios apreciavam a cerâmica dos gregos e que a estes agradava a vidraria dos egípcios, ou ainda, o comumente citado caso dos armazéns de bairro. O dono do armazém desenvolve um relacionamento pessoal com a clientela, passa a conhecer as suas preferências de consumo e ainda manda avisar em casa quando o seu produto já chegou na loja.

O propósito do CRM, hoje, continua sendo o mesmo, fidelizar o cliente, porém algumas características do ambiente de hiper-competição no qual as empresas estão inseridas tornam o conceito mais complexo, tais como, o tamanho dos negócios, a diversificação dos canais de comercialização e distribuição, a velocidade no lançamento de novos produtos, o 
aumento da conscientização do consumidor sobre seus direitos e a preocupação com a responsabilidade sócio-ambiental.

Na era pós-industrial, ao mesmo tempo em que a gestão do relacionamento com o cliente é mais complexa, para ter participação de mercado é necessário primeiro concentrar-se na participação de cada cliente. A idéia presente é reter o cliente e vender a ele o máximo de produtos ou serviços possíveis em um longo período de tempo, incluindo diferentes linhas de produtos.

Rifkin (2001) expressa bem a profundidade deste paradigma ao estabelecer um paralelo da era pós-industrial, denominada por ele de "A Era do Acesso", com a era da manufatura. Segundo o autor, controlar o cliente é tão importante nesta nova era quanto o era controlar a produtividade do trabalhador na era da manufatura. A tecnologia deixa de ser o cronômetro e a linha de montagem para dar à tecnologia de relacionamento. A perspectiva de produção cede lugar à perspectiva de marketing, a noção de fazer vendas é substituída pela noção de estabelecer relações.

Alinhado com esta visão, ganha corpo o conceito de gestão do ciclo de vida do cliente, expresso no termo "lifetime value" (LTV - o valor ao longo da vida). O LTV de um cliente representa a rentabilidade que ele trará ao longo de sua existência, baseado na projeção do valor atual de todas as suas compras futuras, deduzidos os custos de marketing e dos serviços ao cliente gerados para assegurar e manter um relacionamento para toda a vida.

Com o intuito de identificar os fatores críticos de sucesso para a implementação do CRM numa organização, este artigo mostra o resultado de um estudo de caso realizado em uma empresa global do ramo de engenharia eletroeletrônica. A análise pautourse em aspectos relacionados à estratégia corporativa e à estrutura do CRM. 


\section{CONCEITO DE CRM}

O CRM agrega uma filosofia e ferramentas adequadas para monitorar e perpetuar o relacionamento com o cliente. O CRM não está vinculado a um programa específico e é mais abrangente do que a utilização de uma ferramenta ou a formação de um banco de dados sobre o cliente.

Para maior esclarecimento, elencamos algumas definições sobre o assunto:

Segundo Brent Frei, fundador da Onyx Software, CRM é um conjunto de processos e tecnologias para gerenciar relacionamentos com clientes efetivos e potenciais e com parceiros de negócios por meio do marketing, vendas e serviços, independentemente do canal de comunicação. (GREENBERG, 2001, p.5).

(...) são as atividades que o negócio desenvolve para identificar, qualificar, adquirir, desenvolver e guardar, aumentando a lealdade e rentabilidade do cliente através da entrega do produto ou serviço certo, ao cliente certo, através do canal certo, no tempo certo e no custo certo. CRM integra vendas, marketing, serviço, planejamento de recursos operacionais e as funções de gerenciamento do canal de suprimento, através da automação dos processos, tecnologia de soluções e recursos de informação para maximizar cada contato com cliente. CRM facilita o relacionamento entre operações, seus clientes, parceiros, fornecedores e empregados. (GALBREATH, 1999 apud GALBREATH, 1999, p. 162).

CRM é uma estratégia de negócio voltada ao entendimento e à antecipação das necessidades dos clientes atuais e potenciais de uma empresa. Do ponto de vista tecnológico, CRM envolve capturar os dados do cliente ao longo de toda a empresa, consolidar todos os dados capturados interna e externamente em um banco de dados central, analisar os dados consolidados, distribuir os resultados dessa análise aos vários pontos de contato com o cliente e usar essa informação ao interagir com o cliente através de qualquer ponto de contato com a empresa. (PEPPERS\&ROGERS GROUP, 2004, p.59)

A análise destas e de outras interpretações sobre CRM deixa claro tratar-se de um conceito abrangente, que ultrapassa as fronteiras dos departamentos e/ou processos, dos níveis hierárquicos e as fronteiras interorganizacionais, e traz consigo a exigência de elevar as 
questões do cliente ao nível estratégico da organização. O conceito de CRM envolve pessoas, tecnologia, revisão de processos, e informações alinhados com uma estratégia voltada para o cliente - (Figura 1)

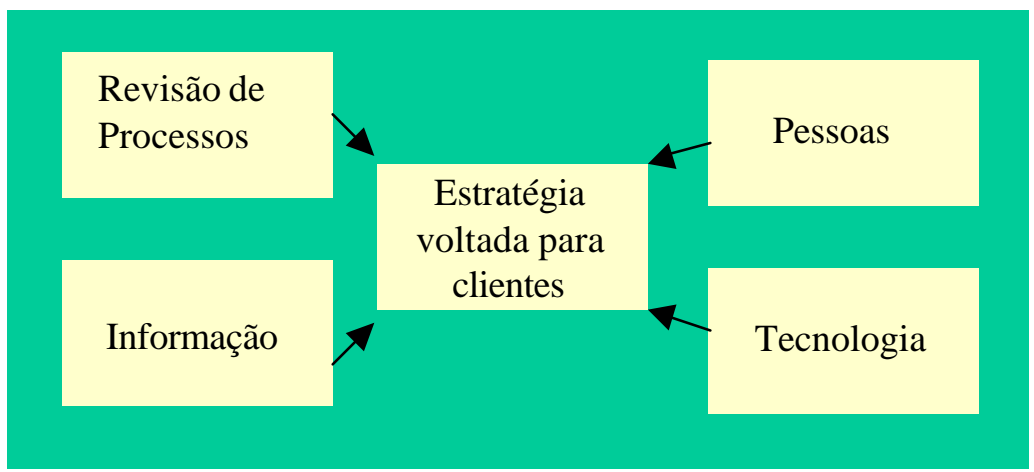

Figura 1: Conceito de CRM

Fonte: elaborado pelas autoras.

Galbreth e Rogers (1999, p. 162), reforçam a importância estratégica da gestão do relacionamento com o cliente. Para os autores, CRM é uma estratégia para vantagem competitiva, é uma transformação da filosofia e de um ideal de como os negócios devem competir no século 21.

A falta de uma estratégia adequada para o cliente também tem sido apontada como um dos quatro fatores de risco de fracasso na implementação do CRM. (RIGBY, 2002).

Definir uma estratégia voltada para o cliente, inclui dimensionar o impacto nos resultados globais que são esperados com a gestão do relacionamento com o cliente, uma vez que investimentos em tecnologia de CRM podem ser expressivos. Da mesma maneira, as definições quanto à segmentação do mercado, necessidades destes clientes, e estratégias e objetivos comerciais são importantes definições para dimensionar os esforços que serão empreendidos e o retorno esperado.

Mckenna (1992) faz uma distinção entre empresas que utilizam estratégias tradicionais e empresas que utilizam estratégias centradas no consumidor. Nas estratégias tradicionais o posicionamento é centrado na empresa e pressupõe um ambiente estático, as empresas decidem primeiro como querem se posicionar (exemplo: baixo preço, qualidade), 
em seguida escolhem um slogan que resume a mensagem desejada e investem em anúncios e promoções até que o slogan seja amplamente reconhecido.

A contraposta é a estratégia de posicionamento dinâmico, baseada no conhecimento da estrutura do mercado, através do desenvolvimento de relações com fornecedores, distribuidores, investidores, clientes e outras pessoas e empresas do mercado. O ciclo de feedback torna-se essencial. Clientes e outros influenciam a mudança nos produtos e serviços, através da participação nessas relações (Figura 2).

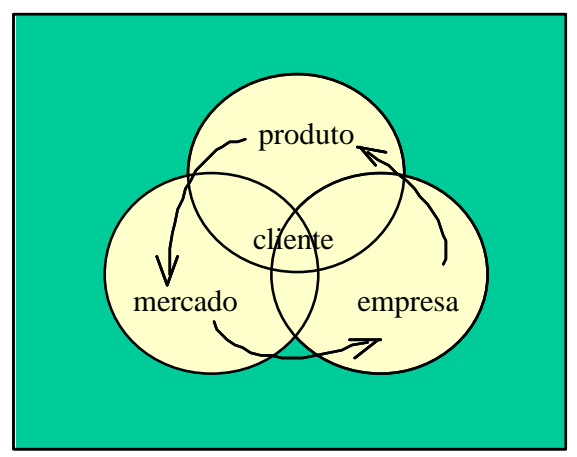

Figura 2: Estratégia de Posicionamento Dinâmico

Fonte: Mckenna (1992, p. 49)

O papel do CRM é justamente integrar as informações que podem vir de dentro da empresa ou das diversas partes externas que interagem com a empresa e transformá-las em conhecimento para a gestão do relacionamento com o cliente. As informações integradas propiciam à empresa conhecer o perfil de seus clientes, por que compram, quando compram, o que compram, quem e quais são os clientes de maior valor e, assim, desenvolver estratégias adequadas para manter o relacionamento com o cliente, maximizando o seu valor para empresa.

Do ponto de vista do cliente, o CRM ajuda a empresa no desenvolvimento de produtos e serviços adequados às suas necessidades.

A estratégia voltada para o cliente somente se concretiza com o processo de ouvir a voz do cliente, interpretá-la e tomar ações que vão de encontro às suas necessidades. 
Galbreath e Rogers (1999) definem como pilares de sustentação de um projeto de

CRM, 3 áreas distintas para satisfação das necessidades dos consumidores: (1) atendimento às necessidades dos clientes, (2) relacionamento personalizado, (3) serviços e suporte pós-venda.

\section{Atendimento às Necessidades dos Clientes}

$\mathrm{O}$ atendimento às necessidades dos clientes inclui a compreensão das necessidades que estão implícitas e não são declaradas. Carvalho (1997), explica que existem casos em que o consumidor "esquece" de alguns requisitos básicos (ex.: avião - esquece de pedir um avião seguro, que não caia, mas se lembra de pedir bom atendimento e pontualidade; ou então não age de acordo com o que diz - afirma preferir comida sem açúcar, mas consome com açúcar).

Os requisitos que são inerentes ao negócio ou os requisitos estatutários não serão declarados pelo cliente, que assume que por atuar em determinado segmento a empresa tenha condição de atendê-los.

Também é importante descobrir e atender as necessidades que os competidores não puderam preencher. Faz-se necessário entender porque os consumidores compram, quais necessidades os produtos da empresa ou serviços preenchem e definir os atributos e características dos produtos com relação ao dos competidores a fim de encontrar novas oportunidades.

\section{Relacionamento Personalizado}

Sem informações que permitam manter um histórico do cliente, cada contato com a empresa corre o risco de parecer o primeiro contato, tendo que ser retomada a identidade do cliente, sem que haja uma evolução no relacionamento e um tratamento personalizado.

O relacionamento personalizado requer conhecimento sobre o cliente, é mais do que ouvir o cliente, inclui utilizar o feedback para melhorar processos, produtos e o relacionamento. Entrevistas realizadas com 24 especialistas em gerenciamento do conhecimento de clientes, revela que uma empresa precisa mais do que transação de dados 
para ganhar percepção sobre o cliente e que suas empresas são bem sucedidas porque elas consideram as pessoas atrás das transações. Também, as atividades de gerenciamento do conhecimento têm objetivos bem definidos: - segmentar a base de clientes, priorizar os clientes, saber o que os clientes querem, gerar confiança nos clientes, inovar os produtos existentes, gerar serviços, ter maior sucesso nas vendas cruzadas (DAVENPORT et al., 2001).

\section{Serviços e Suporte Pós-Venda}

Galbreath e Rogers (1999) ressaltam que para muitas empresas, a venda é um fim em si mesma. Terminada uma venda partem para outra sem se preocupar com a satisfação do cliente ou o que eles queiram ou precisem em relação à venda efetuada. O resultado desta postura é que $68 \%$ dos clientes deixam uma empresa sem citar um motivo especial para isto, o que talvez possa ser explicado por esta lacuna no processo de vendas.

O processo de ouvir a voz do cliente e transformá-la em produtos e serviços que agreguem valor ao cliente, requer o alinhamento da estrutura organizacional em torno da visão do cliente.

A filosofia do CRM compreende o desenvolvimento da visão estratégica a respeito do cliente, que por sua vez deve gerar mudanças na cultura organizacional, e uma série de outras ações para concretizar a visão, como definição de objetivos de retenção e satisfação dos clientes e mudanças nos processos chaves.

A tecnologia desempenha um importante papel no sentido de alinhar os processos internos aos canais de contato com o cliente.

A tecnologia do CRM é uma combinação de software de CRM, com telefonia, e outros canais, como e-mail, Internet e fax.

Do ponto de vista dos sistemas, CRM é a integração dos módulos de automatização de vendas, gerência de vendas, telemarketing e televendas, serviço de atendimento e suporte ao cliente (SAC), automatização de marketing, ferramentas para informações gerenciais, WEB e comércio eletrônico. (PEPPERS\&ROGERS GROUP, 2004, p.60). 
As tecnologias de CRM foram desenvolvidas depois das tecnologias de ERP. Os

Sistemas de ERP concentram-se no interior das empresas e seus processos (atividades de back office). As soluções de CRM são voltadas ao cliente, ao relacionamento e, portanto, às vendas (atividades de front office). Por isso, as empresas que estão se voltando para a implantação das tecnologias de CRM enfrentam o desafio de fazer a compatibilização destas ferramentas com os sistemas de ERP já implementados.

\subsection{Automação da Força de Vendas}

Há duas dimensões de tecnologia de CRM: aplicações dirigidas ao cliente, aquelas que o cliente efetivamente experimenta e pelas quais interage com atendentes, site ou sistemas, e aplicações dirigidas à empresa, que se dividem em automação da força de vendas, automação do marketing e serviço e suporte a clientes. A proposta deste artigo é detalhar sobre a automação da força de vendas em função da relação com o estudo de caso proposto.

Segundo Greenberg (2001), os produtos encontrados no mercado para automação da força de vendas precisam desempenhar as seguintes funções:

- Gerenciamento de Contatos: informações básicas sobre o contato e o cliente, visualização da conta como um todo.

- Gerenciamento de Contas: Gerenciamento de contas individuais, com links para tudo que se relacione às oportunidades e negócios com aquele determinado cliente.

- Gerenciamento de Oportunidades: Pode-se visualizar a oportunidade, a empresa, as pessoas envolvidas no possível negócio, o potencial de fechamento e seus prováveis resultados, o estágio em que se encontra no processo de venda e a possível data de fechamento. 
- Gerenciamento do Processo de Vendas: ex: prospecção, clientes potencialmente melhores, qualificação, oportunidade, construção da visão de compra, concorrência, negociação, fechamento (ganho ou perdido).

- Previsão de Vendas: planilhas, produção de cenários.

- Geração automática de orçamentos e pedidos

As tecnologias de automação da força de vendas englobam:

- Sincronização de dados: atualização de informações entre computadores não conectados - laptop, hardware móvel e desktops. O sistema rastreia as mudanças sempre que os vendedores se conectam ao sistema por meio de modems ou rede local.

- Ferramentas para a geração de relatórios.

- Força de vendas móvel: registro dos contatos feitos por ligação ou e-mail.

Automatizar as vendas significa padronizar o processo de vendas com o apoio da tecnologia. Além de abranger todas as etapas do processo de vendas, o sistema deve permitir a conexão com as atividades de apoio, tais como o sistema de suporte ao cliente, cobrança e expedição. Com a automatização, a empresa passa a ter um banco de dados único com as informações do cliente, o que amplia a visão que se tem do mesmo e permite gerenciar o relacionamento. $\mathrm{O}$ fato de poder compartilhar as informações internamente permite desenvolver soluções específicas em termos de produtos, serviços e encaminhamento de problemas. A automação também reduz o tempo de ciclo do atendimento ao cliente.

A literatura sobre CRM aponta como uma das principais falhas no processo de automação da força de vendas o fato do vendedor sentir a sua posição ameaçada pelo fato de não ser ele mais o detentor das informações sobre o cliente.

As estratégias de implementação recomendadas incluem a conscientização do vendedor sobre os benefícios da tecnologia no processo de vendas, como ter à disposição o histórico de vendas e da relação do cliente com as demais áreas da empresa, a economia de 
tempo pela desburocratização do processo e a facilidade no acompanhamento do pedido do cliente. Recomenda-se, também, a revisão da remuneração dos vendedores atrelada a toda iniciativa de CRM.

\section{CRM NO MERCADO BUSINESS-TO-BUSINESS (B2B)}

Uma análise das características do mercado business-to-business, em relação ao mercado de vendas direto ao consumidor (vide quadro 1), mostra que a gestão do relacionamento com o cliente assume uma dimensão muito maior quando aplicada ao mercado B2B.

O mercado business-to-business é um mercado de tamanho menor em número de clientes e é composto por empresas de grande porte. O valor econômico das negociações é alto. Por isso, o valor de um único cliente ao longo de sua existência pode ser enorme. A perda de um único cliente pode ter um impacto negativo para o faturamento da empresa, o que faz com que maior ênfase seja dada na manutenção dos clientes existentes do que na aquisição de novos clientes. O interesse da empresa que atua neste segmento é construir um relacionamento baseado na confiança e no interesse mútuos e ainda, entregar produtos e serviços de alto valor ao cliente.

Quadro 1: Comparativo das Características dos Mercados de Venda Direta ao Consumidor (B2C) e de Venda Direta para Empresa (B2B)

\begin{tabular}{|l|l|}
\hline Marketing Direto ao Consumidor & Marketing Direto Business-to-Business \\
\hline Compram para benefício próprio & Compram para benefício da organização \\
\hline $\begin{array}{l}\text { Decisões de compras não envolvem tanto outras } \\
\text { pessoas }\end{array}$ & $\begin{array}{l}\text { Freqüentemente as decisões envolvem várias } \\
\text { pessoas }\end{array}$ \\
\hline Grupos de compradores individuais & Múltiplos Grupos de Compradores \\
\hline Processo informal de compras & Processo formal e informal de compras \\
\hline Baseado nas transações & Baseado no relacionamento \\
\hline $\begin{array}{l}\text { Tamanho médio relativamente pequeno de } \\
\text { compras }\end{array}$ & Tamanho médio de compras tende a ser grande \\
\hline Lifetime value relativamente baixo & Lifetime value pode ser muito amplo \\
\hline Facilidade de chegar até as pessoas & Dificuldade de chegar às pessoas \\
\hline
\end{tabular}



Focado em processos de relacionamento

Fonte: Pesquisa realizada por Hunter Business Group (STONE e JACOBS, 2001, p. 42)

Uma outra característica do mercado B2B é o contato com representantes, compradores e fornecedores de outras empresas que compram ou influenciam a compra para as empresas que representam, o que torna o processo de venda mais complexo, exigindo negociação com múltiplos grupos e uma estrutura para controlar as fases desta negociação. Torna-se importante investir na construção e manutenção de um relacionamento com estes atores que influenciam ou dirigem as compras.

Devido o alto valor de um único cliente e a complexidade das negociações, destacam-se dua s contribuições do CRM para o mercado B2B: (1) o aumento da oportunidade de vendas (enquanto reduz custos de vendas) e (2) a manutenção do relacionamento com os clientes existentes (STONE e JACOBS, 2001).

O CRM facilita o desenvolvimento de ações que conduzam ao relacionamento de longo prazo e que beneficiem ambas as empresas. Pode-se utilizar as informações do banco de dados para determinar que outros produtos podem ter aplicação para o cliente, obter indicação de outros compradores, tratar as reclamações dos clientes, determinar os riscos com determinados clientes ou mercados-alvo e continuamente monitorar e medir o relacionamento com o cliente.

Quanto ao aumento das oportunidades de vendas, após ganhar um cliente, a empresa pode prosseguir com a penetração da sua estratégia, procurando aprofundar o conhecimento a respeito do cliente, a respeito dos seus negócios e com isto oferecer produtos e serviços customizados. 


\section{ASPECTOS METODOLÓGICOS DA PESQUISA}

Com o objetivo de melhor identificar os fatores críticos para a implementação do CRM, tanto no que concerne ao impacto estratégico, como nos aspectos estruturais de sua implementação, optoutse pela abordagem de estudo de caso, que permitiria analisar estes fatores (YIN, 1991).

Os critérios para a escolha do caso a ser analisado foram: a existência de um programa de CRM, uma estrutura organizacional com a função Gerenciamento de Cliente formalizada e a presença de uma arquitetura abrangente de sistemas de informação.

Com base nestes critérios, foi selecionado o caso de uma empresa global em engenharia eletroeletrônica que desenvolve o CRM. Uma vez selecionado o caso, foram levantados documentos e elaboradas entrevistas com atores da corporação.

O instrumento de pesquisa elaborado foi um roteiro de entrevista, com questões abertas, que englobam os seguintes aspectos: caracterização da empresa; alinhamento entre estratégia e CRM; CRM e a estrutura organizacional; infraestrutura tecnológica do CRM; etapas de implementação e fatores críticos do processo de implementação e resultados obtidos.

\section{ESTUDO DE CASO}

A Siemens é uma empresa global em engenharia eletroeletrônica, formada há 150 anos. Está no Brasil desde 1867 e conta com aproximadamente 7000 funcionários. Atua no desenvolvimento e fabricação de produtos de ponta; planejamento e instalação de sistemas e projetos complexos e na elaboração de diversas soluções dedicadas, de acordo com as exigências dos seus clientes. 
A empresa atua em mais de 190 países, fornecendo tecnologia em Informática e Comunicações nas áreas de, Indústria, Energia, Transportes, Medicina, Técnica Automotiva e Iluminação.

Uma das áreas de atuação da Siemens é a divisão Information and Communications (I\&C) que oferece um portfólio completo de soluções, através de sistemas, equipamentos e serviços (projetos, desenvolvimento, operação e manutenção), convergentes para tornar os negócios móveis em qualquer segmento de mercado, seja ele de operadoras de telecomunicações, indústria, hotelaria, saúde, transporte, comércio, etc.

Para atender estes segmentos de mercado a I\&C está estruturada por divisões, conforme demonstra o Quadro 2.

Quadro 2 - Estrutura da Divisão de Information and Communications

\begin{tabular}{|l|l|}
\hline Divisão & Atividade \\
\hline ICM - Information Comunication Móbile & negócios de telefonia celular \\
\hline SBS - Siemens Business Service & $\begin{array}{l}\text { serviços baseados em Tecnologia da Informação para } \\
\text { otimização dos processos empresariais. } \\
(\text { e-business, } m \text {-business e outsourcing })\end{array}$ \\
\hline ICN - International Comunication Networks & redes de comunicações \\
\hline GB - General Business & $\begin{array}{l}\text { contas gerais: Prefeituras, Sony, Sigmafone, etc. } \\
\text { CI - Canal Indireto: distribuidores e revendedores. }\end{array}$ \\
\hline
\end{tabular}

Fonte: Elaborado pelas autoras com base nos dados obtidos nas entrevistas

A divisão ICN é subdividida em Carrier, que lida com as operadoras - Telemar, Telefônica, BCP etc - e Enterprise, constituída de outras empresas, que não são operadoras de telefonia. A área de Enterprise se subdivide em três outras áreas, segundo o porte dos clientes, como por exemplo grandes contas (major accounts: HSBC, Varig, Ford, etc). 
Os clientes foram agrupados nas áreas acima, considerando aspectos de segmentação do mercado, como porte, potencial e volume de compra e considerando as exigências dos clientes em relação à complexidade dos produtos e soluções.

Os clientes são atendidos pelas Divisões de Vendas e de Negócios. A estrutura de vendas conta com 09 Regionais, 02 Escritórios de Vendas, 14 distribuidores, 35 revendedores e 22 representantes, distribuídos geograficamente pelo Brasil.

Dentro de cada Divisão de Negócio é possível saber quem são os clientes atuais, exclientes e clientes potenciais.

Para cada segmento em que atua, a Siemens desenvolve ações diversificadas para monitorar as necessidades, os fatores de decisão de compra, os atributos do produto e a sua importância relativa ou valor para os clientes. Tais ações englobam os contatos de vendas (visitas, telefonemas, e-mail, fax, etc.), participações em eventos e feiras, estudos de mercado, captação das informações advindas dos canais de atendimento (internet e centrais de atendimento), relatórios de análise de desempenho por cliente e por produto, visita de promotores e pesquisa de satisfação de clientes. A análise dos registros gerados por estas ações (relatórios, planos, etc.), tem o objetivo de entender e antecipar as necessidades dos clientes e incorporar aos produtos ou serviços os fatores de decisão de compra e os atributos do produto relatados pelo cliente.

A Siemens também tem instituído um Comitê de Gestão de Clientes (CGC) que se reúne mensalmente para avaliar as práticas relativas à imagem e conhecimento do mercado e propor melhorias e novos processos, com base nos resultados da Pesquisa de Imagem e Marca e informações geradas pelos acessos dos clientes.

A interface com o cliente acontece nas etapas de Pré-vendas, Pós- venda e Service.

Pré-vendas é responsável pela elaboração de ofertas e propostas. 
No Pós-Venda, o cliente tem o contrato assinado e os contatos são feitos com a intenção de acompanhar ou monitorar a fabricação e entrega do seu produto ou serviço.

O service é responsável pela implantação da solução comercializada e pela manutenção técnica. Os clientes são atendidos de acordo com um dos três planos de manutenção que possuem, definido em contrato, que determinam em quais dias da semana e em quais horários serão atendidos, bem como prazo para os atendimentos de urgência.

Os canais disponíveis para o contato do cliente nas fases de pré-venda, pós-venda e service estão descritos no quadro 3. Também estão indicados os fornecedores de tecnologia de CRM predominantes (SAP ou Siebel). As atividades de cada um dos canais estão descritas a seguir.

Quadro 3 - CANAIS DE ACESSO AO CLIENTE NAS ATIVIDADES DE PRÉ-VENDA, PÓS-VENDA E SERVICE

\begin{tabular}{|l|l|}
\hline Pré-Venda & $\begin{array}{l}\text { Central de Atendimento: 0800 - vendas enterprise e 0800 } \\
\text { corporativo. } \\
\text { CCI - Customer Care Interface } \\
\text { Internet - "fale conosco" - www.siemens.com.br/IC. } \\
\text { Tecnologia: Software SIEBEL. }\end{array}$ \\
\hline Pós-Venda & Central de Atendimento 0800. Tecnologia SAP. \\
\hline $\begin{array}{l}\text { Service (SAS) Serviço } \\
\text { Autorizado Siemens }\end{array}$ & $\begin{array}{l}\text { Central de Atendimento } \\
\text { Tecnologia SAP. }\end{array}$ \\
\hline $\begin{array}{l}\text { Contato com Vendas } \\
\text { (central, regional e de } \\
\text { atendimento especial } \\
\text { no ambiente do cliente) }\end{array}$ & $\begin{array}{l}\text { Freqüência conforme natureza do negócio e cliente, com registro } \\
\text { no SIEBEL. }\end{array}$ \\
\hline
\end{tabular}

Fonte: Elaborado pelas autoras com base nos dados obtidos nas entrevistas

As Centrais de Atendimento de Pré-Venda (call center) registram oportunidades de negócios e reclamações, que são encaminhados internamente via SIEBEL.

A Siemens mantém uma estrutura de atendimento nas regionais de vendas, são os chamados CCI - Customer Care Interface. Os CCI's atendem clientes interessados em 
produtos e serviços e geram oportunidades de negócios para clientes GB ou MA, e também registram reclamações de clientes.

Os clientes tomam conhecimento dos canais de atendimento através de correspondência emitida pela Divisão de Negócios, por meio de divulgação na Nota Fiscal ou por meio da Internet.

\subsection{Automação da Força de Vendas}

O início da automação se deu a partir de abril/2000, com a implantação do software da empresa Siebel Systems, uma das líderes de mercado em CRM, na área de Pré-Vendas.

A Siemens já possuía a plataforma ERP/SAP, que foi integrada ao Siebel. A base de dados do cliente é única.

Os atendentes da Central de Atendimentos da matriz, dos CCI's (regionais) e pessoal de vendas utilizam a plataforma Siebel (ver quadro 3). As principais possibilidades de trabalho através do sistema, e as vantagens obtidas são as seguintes:

- manter base de dados única do cliente, o que facilita a organização de mala direta e agiliza o cadastro.

- manter histórico do relacionamento com o cliente, permitindo uma abordagem proativa nas vendas, bem como a compreensão das necessidades dos clientes.

- gerar e monitorar oportunidades de negócios, as quais são registradas, encaminhadas à área responsável via sistema e todos os futuros contatos gerados, até a venda ou não do produto ou serviço.

- gerenciamento das contas dos clientes: por que compram, quando compram, etc.

- previsões de vendas: analisando o encaminhamento das oportunidades de negócios é possível antecipar a previsão de vendas e desenvolver ações para otimizá-las. 
- planejamento de vendas: a análise das oportunidades e visitas aos clientes permite monitorar as ações dos concorrentes e desenvolver atividades.

\section{2 - Análise do Caso Siemens}

As forças da automação de vendas, conforme pudemos apurar, parecem concentrarse no aumento da mobilidade do vendedor; utilização de dados para a tomada de decisão; maior suporte da gerência de vendas ao vendedor por meio do acompanhamento do histórico de suas vendas e do encaminhamento que está sendo dado a uma determinada oportunidade; otimização das vendas pelo acesso a informações; postura pro-ativa quanto aos clientes e mercado.

As fraquezas da automação residem em fazer com que o vendedor transfira para a base de dados as informações geradas em visitas aos clientes. Para ele, o CRM pode representar uma ameaça pela possibilidade de controle sobre as suas vendas. Para estimular o uso do sistema, a Siemens exige a utilização e apresentação de relatórios gerados pelo Siebel, e também acompanha as campanhas de vendas utilizando as informações contidas no sistema.

A Estrutura de CRM voltada à automação da força de vendas possibilita que a empresa gerencie contatos, contas e oportunidades. A própria aplicação da ferramenta de CRM provê, de forma padronizada, que a estrutura seja implementada.

O caso não cita mudanças culturais significativas ou nos processos, uma vez que a empresa já possuía uma estrutura de ERP, bem como normas de qualidade em funcionamento.

A Gerência de Vendas estima que a produtividade do vendedor possa ter aumentado em $30 \%$ pela mobilidade alcançada, porém não pudemos comprovar esta informação com dados, uma vez que o término da implantação do sistema era recente.

$\mathrm{O}$ aumento da produtividade de vendas e manutenção do relacionamento com clientes, as duas maiores contribuições do CRM, têm o respaldo de ações estratégicas da 
empresa, como as pesquisas de imagem e de satisfação dos clientes e a formação do Comitê de Gestão de Clientes.

\section{CONSIDERAÇÕES FINAIS}

O artigo enfocou uma das dimensões da aplicação do CRM, a automação da força de vendas, no mercado business-to-business, onde o valor ao longo da vida, valor de um único cliente ao longo de sua existência, pode ser enorme. A pesquisa foi realizada com o objetivo de analisar aspectos relacionados à estratégia corporativa e à estrutura do CRM. Pôde-se constatar que alguns fatores estão atrelados ao sucesso na implantação de um projeto de CRM: fazer parte de decisões estratégicas da empresa, que incluam monitorar a satisfação do cliente e a conscientização e envolvimento do staff da empresa. Sem uma estratégia clara de atendimento ao cliente, que permeie todos os níveis hierárquicos da empresa, as chances de sucesso do CRM são mínimas.

\section{REFERÊNCIAS}

CARVALHO, M.M. QFD: Desdobramento da Função Qualidade. In: CARVALHO, M.M. QFD: uma ferramenta de tomada de decisão em projeto. Florianópolis. Universidade Federal de Santa Catarina, Departamento de Engenharia de Produção e Sistema, Tese (Doutorado). Disponível em: < http://www.eps.ufsc.br/teses97/marly/cap2.htm - 2.3.1>. Acesso em: 22/12/04.

DAVENPORT, Thomas H., et al. How do they know their customers so well ? MIT Sloan Management Review. Cambridge Massachusetts, vol. 42, ed. 2, p. 63 -73, winter 2001.

GALBREATH, Jeremy; ROGERS, Tom. Customer Relationship Leadership: a Leadership and Motivational Model for the Twenty-First Century Business. TQM Magazine. Bradford, v.11, n.3, p. 161-171, v. 11, n.3, 1999.

GALBREATH, Jeremy. Desmystifying customer relationship management: it's as easy as one-two-three. 1999. Trabalho não publicado. In: GALBREATH, Jeremy; ROGERS, Tom. 
Customer Relationship Leadership: a Leadership and Motivational Model for the TwentyFirst Century Business. TQM Magazine. Bradford, v.11, n.3, p. 161-171, v. 11, n.3, 1999.

GREENBERG, Paul. CRM na Velocidade da Luz. HSM Management. Book Summary 2, p. 4-21, 2001.

McKENNA, Regis. Marketing de Relacionamento: estratégias bem sucedidas para a era do cliente. 19.ed. Rio de Janeiro: Campus, 1992. 254p.

PEPPERS\&ROGERS GROUP. CRM Series - Marketing 1 to 1. 3.ed. São Paulo, 2004, 108p. Disponível em: www.1to1.com.br/pag-guia.php3. Acesso em: 22/12/04.

RIFKIN, Jeremy. A Era do Acesso: a transição de mercados convencionais para networks e o nascimento de uma nova economia. São Paulo: Makron Books, 2001. 264p.

RIGBY, Darrell K.; REICHHELD, Frederick F.; SCHEFTER, Phil. Avoid the four perils of CRM. Harvard Business Review. Massachusetts, Vol. 80, ed 2, p.101 -109, fev, 2002.

STONE, Bob; JACOBS, Ron. Business-to-Business direct marketing. Resenha de: Successful Direct Marketing Methods. STONE, Bob; JACOBS, Ron. McGraw-Hill, 2001. New Book Selection. p.41- 49, [2001?]

YIN, Robert K. Case Study Research: Design and Methods . Newbury Park: Sage Publications, 1991. 166p. 